\title{
Uma controvérsia em torno da educação científica: partidários e críticos
} do construtivismo ${ }^{+*}$

Jenner Barretto Bastos Filho ${ }^{1}$

Instituto de Física - Universidade Federal de Alagoas

Programa de Pós-graduação em Ensino de Ciências e Matemática - UFAL

Mestrado Nacional Profissional em Ensino de Física - UFAL-Polo 36

Maceió - AL

\section{Resumo}

Analisamos alguns pontos da controvérsia entre construtivistas e seus críticos. Argumentamos que as necessidades de conhecimento prévio e de protagonismo do aprendiz em sua própria construção do conhecimento são conciliáveis tanto com o imprescindivel legado cultural recebido pelo aprendiz quanto com os treinamentos por automação e repetição de procedimentos que podem liberar potencialidades para habilidades mais criativas.

Palavras-chave: Construtivismo; Crítica ao construtivismo; Controvérsia; Educação Científica; Possível Conciliação.

\begin{abstract}
Some points of the controversy among the constructivists and critics are analyzed. We claim that the requirements of previous knowledge and self-learning attitudes are both in perfect conciliation with the cultural legacy acting on the learner, and with the needs of training and automatic procedures which can provide space for potentialities of more creative skills.
\end{abstract}

Keywords: Constructivism; Criticism to Constructivism; Controversy; Scientific Education; Possible Conciliation.

\footnotetext{
${ }^{+}$A controversy around the scientific education: the supporters and critics of Constructivism

* Recebido: maio de 2015.

Aceito: junho de 2015.

1 E-mail: jenner@fis.ufal.br
} 
Artigo dedicado ao Prof. José Maria Filardo

Bassalo pelos seus 80 anos de idade que serão

completados no dia 10 de setembro de 2015.

\section{Introdução}

A nossa intenção aqui neste artigo é de homenagear o nosso querido José Maria Filardo Bassalo pelos seus 80 anos de idade que serão completados no próximo dia 10 de setembro deste ano da graça de 2015. Dentre tantos aspectos possíveis para enfoque em um artigo do gênero, escolhemos um de decisiva importância: a imprescindível educação científi$c a$, se o que quisermos é mirar o nosso futuro com renovadas esperanças. Dentro do tema amplo da educação científica, escolhemos emitir algumas considerações sobre a controvérsia em torno do construtivismo e para tal traremos para discussão um recorte delimitado de posições se bem que, a nosso ver, constitua-se em um ponto de partida para ensejar o debate.

A controvérsia em torno do construtivismo está por toda a parte. Ela comporta muitas posições em um largo espectro que vai desde aquelas dos maiores apologistas àquelas dos maiores detratores das qualidades dessa adoção para o ensino de ciências, adoção essa que é, ao mesmo tempo, tanto pedagógica quanto epistemológica.

De maneira panorâmica e grosso modo, no que concerne ao ensino de ciências podemos caracterizar as correntes construtivistas como aquelas que enfatizam a importância imprescindível do conhecimento prévio do aprendiz bem como de seu irrenunciável protagonismo na construção de seu próprio conhecimento. Deste modo, grande parte da controvérsia em torno das adoções construtivistas ou não se dá justamente quanto às respectivas naturezas tanto dessa centralidade quanto desse protagonismo. Isto porque, se essa centralidade for exclusivamente atribuída ao aprendiz, então dificilmente seria valorizado o papel do professor que, em princípio, é o portador por excelência do legado cultural sem o qual o aprendiz estaria abandonado a uma contínua e recorrente reinvenção da roda. Em outras palavras, e já procurando adiantar alguns pontos que traremos à baila aqui, diríamos que a complexidade envolvida na questão do conhecimento é de tal monta que enfaticamente nos recomenda a admitir outros protagonismos e outras centralidades como necessariamente intervenientes no processo.

Muitos professores, educadores e cientistas atribuem qualidades notáveis ao construtivismo enquanto outros são críticos implacáveis dessa adoção, a ponto de considerá-la como responsável pelos desatinos que acometeram e ainda acometem a educação científica no nosso país e, inclusive, nos demais países. Somos da opinião que as controvérsias desempenham papel importante e não há razão alguma para que os partidários de quaisquer que sejam os pontos de vista legítimos deixem de defender as suas concepções ainda que movidas por fortes convicções. Há, contudo, um limite importante que deve necessariamente ser adotado por todos os intervenientes no debate. É necessário que ele seja respeitoso e para que isso seja alcançado faz-se absolutamente imprescindível que quaisquer intolerâncias motivadas por 
racismos, fascismos, preconceitos étnicos, preconceitos de regionalidade, xenofobias, homofobias e quaisquer outros fundamentalismos intolerantes sejam peremptoriamente recusados e, como tal, não sejam admitidos no debate. Podemos ser tolerantes em relação a tudo, exceto em relação à intolerância. Se formos tolerantes com a intolerância, destruiremos a democracia, o pluralismo e o discurso racional. É, portanto nossa intenção aqui, emitir o nosso parecer sobre o assunto e como vemos o problema.

Cremos que as controvérsias, tal como mostraram os debates ocorridos durante o XIV EPEF (Encontro de Pesquisa em Ensino de Física) realizado em novembro de 2012 em Maresias, SP, sejam excelentes expedientes a fim de que possamos emitir juízos sobre o assunto que, não obstante, devido a sua inerente complexidade, permanecerão sempre recorrentes.

Bassalo contribuiu e continua a contribuir para que várias gerações de estudantes, professores e pesquisadores desenvolvam as suas enormes potencialidades e não se apequenem com vitórias efêmeras que não signifiquem conquistas cognitivas sólidas, sejam elas individuais, sejam elas compartilhadas, nem tampouco se afastem dos sérios compromissos éticos com as gerações, tanto as atuais quanto as vindouras, tanto quanto ainda com o ambiente que nos propicia os meios de sustentação da vida.

Não se trata de um mero exercício laudatório para deixar alegre um amigo caríssimo e admirabilíssimo. Bassalo não mereceria apenas isso. O mais relevante que podemos fazer é o de manifestar o nosso apreço e o nosso sincero reconhecimento da importância singular de seu exemplo para o nosso país e principalmente para as gerações vindouras.

\section{A importância dos memoriais}

Sem memoriais, a história se perde. Quem semeia um futuro promissor, sabe necessariamente cuidar de sua História e de seus Memoriais. Deveremos ser capazes de transformálos em exemplos vivos e permanentes de educação. Não se trata apenas de um dever ético; constitui-se também em um dever de quem acredita - por convicção - que a educação liberta, o que é muitíssimo mais importante do que atender às demandas do mercado. Não é à toa que povos, culturas, civilizações ou grupos que querem ter futuro, programaticamente prezam o seu passado e esta é uma referência imprescindível, tanto para exaltar grandes feitos e gloriosas conquistas, quanto para lamentar hediondos episódios. Neste ano de 2015, por exemplo, o Japão trará mais uma vez a lume as tragédias de Hiroshima e de Nagasaki por ocasião do septuagésimo aniversário de ambos os acontecimentos, naturalmente para reafirmar mais uma vez, reiterada e recorrentemente, o seu repúdio e a sua indignação pela hediondez do acontecido, com o fito de clamar a todo o mundo urbi et orbi que tragédias do gênero jamais venham a se repetir.

O dia 13 de maio de 1888 deve ser lembrado e comemorado, embora a abolição da escravatura de então tenha sido incompleta. Ainda não chegou ao seu final a mentalidade e a realidade Casa Grande \& Senzala ainda existentes e Políticas Públicas inclusivas ainda são 
imperiosamente necessárias, ainda que o Brasil de 2015 seja sobremaneira melhor que o Brasil de 1888. Do ponto de vista educacional o percentual de pessoas não letradas de 2015 é sensivelmente menor que o correspondente percentual em 1888, mas o simples fato de ainda termos pessoas não letradas é sumamente grave e tal situação urge ser superada. Felizmente, há em nosso país uma consciência crescente de que esse legado não deixe de orientar o futuro, enquanto necessária referência, tanto no que concerne ao que deve ser preservado quanto ao que deve ser repudiado, quanto ainda para nos orientar acerca do que deve ser transformado. Portanto, haveremos de considerá-lo com o fito de mirar e construir o nosso futuro, tão bem quanto pudermos. Desse modo, os memoriais e, enfim, o cultivo pela História constituem-se em elementos essenciais se quisermos almejar um futuro radioso; isto é verdade, pelo menos, por duas razões: tanto para que não venhamos mais a cometer, por exemplo, ditaduras, escravaturas, massacres, crimes ambientais e quaisquer outras ações predatórias, quanto para marcar, com imenso júbilo, grandes feitos e felizes semeaduras que nos fazem merecedores de um futuro de dignidade e prosperidade e, por isso, são exemplos de educação tomada no seu sentido lato, tanto como dimensão cognitiva, quanto como dimensão ético-política de afirmação da cidadania.

Já nos referimos à importância das controvérsias e dos memoriais para a educação das pessoas. Agora diríamos que a Universidade constitui-se em uma das instituições mais relevantes para os exercícios do pensamento e da autonomia. Por esta razão, ela precisa evoluir e amadurecer para cultivar o pluralismo e a democracia. Ambos, democracia e universidade são imprescindíveis para o exercício das controvérsias e da educação de qualidade. Vamos tecer breves comentários sobre o advento da universidade no Brasil e a imperiosa necessidade de amadurecimento dessa importante instituição.

\section{O advento da Universidade no Brasil}

É recente o advento da Universidade no Brasil; se o nosso marco inicial recair sobre a criação da Universidade de São Paulo, então podemos arbitrar tal advento como o ano de 1934. Anísio Teixeira considerava que os intelectuais brasileiros em tempos anteriores a 1934 caracterizavam-se por singular agrestia uns em relação aos outros (TEIXEIRA, 1998, p. 9899). Quando adotavam uma dada corrente de pensamento de lavra majoritariamente europeia e, talvez, de lavra estadunidense em menor escala, passavam a tratar muito pejorativa e agressivamente aqueles que professavam correntes de pensamento que não compartilhassem com as suas ideias-chave. Tal inadaptação ao convívio plural era atribuída por Anísio à falta de uma real atmosfera universitária de discussão civilizada e de tolerância democrática. Ele tinha esperanças de que essa agrestia fosse superada, ou talvez sensivelmente mitigada com o advento da experiência universitária em nosso país.

É possível que a universidade tenha contribuído para que tal agrestia fosse sobremaneira amenizada, mas, haveremos de convir, que as fontes de autoritarismo são muitas, e que a experiência democrática e os exercícios do pluralismo e do contraditório ainda terão de ser 
cuidadosamente cultivados e isso já se constitui em um dos aspectos da educação tomada no seu sentido mais amplo. Convenhamos também que qualquer descontinuidade do exercício pleno das boas liberdades - tanto intelectual quanto politicamente - certamente implicará desastroso retrocesso. Nós, enquanto professores, e, portanto, como constituintes do espectro de intelectuais de nosso país, deveremos alertar os nossos estudantes bem como quaisquer outras pessoas que nos escutem da necessidade de que o nosso país, que vive desde 1985 até então 2015, 30 anos de período democrático venha sempre a aprimorar a sua democracia imperfeita, pois não existem democracias perfeitas em parte alguma da face da Terra.

\section{IV. É necessário envidar esforços para a superação, tanto quanto possível, da singular agrestia que segundo Anísio Teixeira caracteriza o intelectual brasileiro}

Em novembro de 2012, foi realizado o XIV Encontro de Pesquisa em Ensino de Física (XIV EPEF) em Maresias, São Sebastião, São Paulo, Brasil sob o patrocínio da Sociedade Brasileira de Física ocasião em que As Controvérsias na Pesquisa do Ensino de Física constituíram-se no mote central do encontro. Com a publicação do livro em 2014, que apresentava as discussões em mesas redondas, discussões ampliadas e debates envolvendo várias posições tanto divergentes quanto convergentes, os organizadores não tiveram dúvida de que as controvérsias constituem-se, de fato, em um indício da maturidade alcançada por uma comunidade que já encontra apta a enfrentar os desafios da globalização e da internacionalização das universidades. É neste contexto no qual as controvérsias, e com essas as posições divergentes, devem ser encaradas com absoluta naturalidade e, acrescentaríamos, com um ingrediente a mais de maturidade. Por dever ético de modéstia socrática faz-se imperiosamente necessário que todos nós tenhamos consciência da essencial limitação, mesmo das mais brilhantes, articuladas e abrangentes ideias e teorias. Deste modo, julgamos que a postura que cada um de nós deve assumir neste, e em qualquer outro debate, é a da imprescindível flexibilidade e do devido respeito diante de todos os intervenientes presentes na discussão, o que não deve implicar que pontos controversos de convicção entre os debatedores não possam ser respeitosamente defendidos com a devida ênfase.

\section{V.Ser radical é muito diferente de ser extremista}

Infelizmente, na linguagem cotidiana, as duas notações respectivamente, radical e extremista, assumem a mesma conotação. Assim, quando alguém se refere a uma pessoa dizendo que ela é radical, então, muito frequentemente, essa pessoa, aos olhos das demais pessoas, passa a ser vista como se ela fosse uma pessoa extremista, no sentido mesmo de ser alguém fundamentalista e afastada da razoabilidade.

Argumentamos aqui que a igual conotação atribuída a essas duas notações distintas carrega um enorme inconveniente. E isso pela seguinte razão: ser radical, como a própria palavra encerra, significa ir além da superfície das coisas; significa ir à raiz das coisas. Ora, 
quem vai à raiz das coisas, certamente constata a enorme complexidade da realidade abordada e, deste modo, logo vê que as posturas extremistas somente são compatíveis com as análises daqueles que não passam da superfície das coisas e, por isso, são incapazes de penetrar na raiz das questões. Logo, quem é radical, neste sentido aqui explicitado, não será extremista e sim, diríamos, será alguém até mesmo muito ponderado, pois bem cedo constatará que o extremista é aquele que não vai à raiz e, por conseguinte, por incapacidade mesmo de seu extremismo, não poderá ser radical.

Usaremos a conotação de radicalismo como a de ir à raiz das coisas e não a de ser extremista, que significa muito pelo contrário, não ir à raiz das coisas.

\section{O Construtivismo: um leque imenso de concepções}

O assim chamado Construtivismo é um guarda-chuva de amplo espectro. Por construtivismo pode-se entender um enorme leque de coisas; para dar um exemplo de que o termo 'construtivismo' abriga uma larga gama de abordagens e de campos, ver o artigo (MATTHEWS, 2000, p. 270) bem como as referências nele contidas. Por essa e por outras razões, é recomendável que quem fale sobre o assunto e adote uma dada concepção acerca do que entende por construtivismo, diga com clareza e sem ambiguidades, ou pelo menos com o mínimo possível de pontos ambíguos ou confusos, exatamente o que concebe por construtivismo. Sem que seja feito isso de antemão, então a confusão se instala, pois a própria crítica ao construtivismo padecerá do mesmo mal. Isso é necessário em função do amplo leque de coisas, que não necessariamente dizem respeito ao mesmo significado e que, além disso, muito frequentemente, essas concepções se referem a coisas díspares. Não é de nos estranhar que em semelhante situação sejamos surpreendidos se viermos a nos deparar diante de uma enorme Torre de Babel conceitual.

Traremos ao exame aqui um exemplo de um congresso, cujas atas continham um grande número de contribuições claramente dirigidas contra o construtivismo no contexto da educação matemática. Questionamo-nos como leitores, a que tipos de construtivismo se referiam tais críticas. Ademais, era necessário saber, a nosso modo de ver, se essas realmente tinham ou não pertinência, ou, ainda, se tinham pertinência parcial; além disso, quais eram as concepções que seus críticos esposavam para o ensino da matemática.

Adotaremos aqui uma metodologia de exame um pouco diferente. A partir da crítica ao construtivismo, procuraremos cotejar e confrontar o que dizem e escrevem alguns autores construtivistas, ou tidos como tais, e então, a partir daí, ensejarmos o debate. Esta metodologia de exame, porém, não se revelou muito simples, pois logo constatamos a partir da leitura de parte minúscula da ampla literatura sobre o tema, que a crítica ao construtivismo tem muitos vieses. Deste modo, não sabemos se tal metodologia enseja qualquer esclarecimento acerca da inevitável Torre de Babel. No entanto, ela constituiu-se na maneira com a qual nos acercamos deste problema difícil. Enfatizamos aqui que esta contribuição é apenas um recorte muito delimitado sobre o tema e que a nossa intenção é de apenas suscitar problemas. Desne- 
cessário afirmar que nosso intento é de provocar e ensejar controvérsias e para tal valemo-nos de nossa experiência idiossincrática e pessoal de cerca de 40 anos como professor.

\section{Uma crítica ao construtivismo a partir de uma contribuição a um congresso sobre educação matemática}

Em uma viagem de férias em janeiro de 2015 a Portugal, visitamos a Fundação Calouste Gulbenkian em Lisboa, ocasião em que nos deparamos com as atas de um congresso internacional realizado em novembro de 2008 em Lisboa. Essas atas foram publicadas em julho de 2011, em forma de livro organizado por Nuno Crato intitulado Conferência Internacional Matemática Ensino: Questões e Soluções.

No que concerne à orientação do ensino básico de matemática para os níveis fundamental e médio, impressionaram-nos sobremaneira os trabalhos que se dirigiam contra as correntes assim chamadas de construtivistas. O contributo de Ron Aharoni (2011) constitui-se em um desses trabalhos. Partindo de uma resposta dada pelo grande matemático Gauss acerca de seu próprio método de trabalho que consistia em atuar concretamente e sistematicamente, Aharoni acrescenta mais outro princípio: o de lidar com as palavras (the use of the words).

Aharoni considera que houve na segunda metade do século XX três revoluções no ensino de matemática, cada uma delas dirigida contra um desses três princípios, ou seja, contra o atuar concretamente, contra o trabalhar sistematicamente e contra o uso suficientemente fluente e consciente das palavras.

- A primeira dessas revoluções, ocorrida no final dos anos 50 e continuada nos anos 60 do século XX, foi a da chamada Nova Matemática ou Matemática Moderna que no fundo teria invertido a ordem natural que vai do concreto ao abstrato passando a valorizar o abstrato e reduzindo o concreto a apenas um aspecto particular de uma abstração geral. Isso, segundo o seu parecer, não funcionou.

- A segunda revolução ocorrida nos anos 80 e 90 do século XX foi a do assim chamado aprendizado por descoberta (self-discovery) que parte do princípio segundo o qual é o próprio estudante quem deve construir o seu conhecimento e descobrir por si próprio os segredos da matemática, pois, assim interpretamos, não sendo uma tabula rasa, ele reage sobre o que recebe de fora. Para uma apreciação deste ponto importante, ver (Piaget, 1987). Segundo Aharoni, isto não funcionou e na prática o que se deu foi uma desarticulação do ensino da matemática que, no fundo, redundou na renúncia ao ensino sistemático, justamente uma renúncia daquilo que se constituía em um dos princípios tão caros a Gauss.

- A terceira revolução, segundo Aharoni, que no fundo foi uma resposta às duas primeiras, foi caracterizada pelas palavras de ordem o estudante no centro (the student at the center), mas que no fundo era o professor posto à margem (the teacher pushed aside) o que, segundo ele, inviabilizou a discussão verbal entre grupos fragmentados de estudantes redundando, portanto, na renúncia ao terceiro princípio: o uso da palavras, ou seja, a renúncia à 
capacidade do exercício da argumentação e do rigor que são fundamentais ao sadio ensino da matemática.

\section{Algumas considerações sobre a crítica de Aharoni}

- Atenhamo-nos à primeira revolução apontada por Aharoni. Ficamos a pensar o que realmente se critica, ou seja, qual o alvo preciso da sua crítica. Como ele a expôs com clareza, então fica mais fácil de ser compreendida. Julgamos que ela deva ser seriamente considerada, pois há nela, sem dúvida, aspectos relevantes, mas também consideramos que, à luz da epistemologia, nem tudo o que ela encerra se justifica. Ora, a primeira revolução - a da Matemática Moderna - teria sido parcialmente inspirada no sucesso do lançamento do Sputnik em 1957, pela então União Soviética, o que teria levado os educadores, cientistas e outros estudiosos, precipitadamente ou não, à inferência de que os estudantes russos da antiga União Soviética estariam imersos em um sistema educacional que exercitava um grau de abstração superior comparativamente ao grau correspondente dos estudantes estadunidenses, e daí o sucesso matemático de tais estudantes, pois a partir de suas abstrações teriam mais facilidade de concretizar, a depender da situação específica ou particular. A ideia de valorizar o conhecimento geral e mais abstrato e somente a partir daí situar os casos mais concretos e particulares, talvez decorresse, direta ou indiretamente, de uma crítica epistemológica radical dirigida contra o empirismo puro e o princípio da indução quando esta crítica era exacerbadamente concebida e aplicada sem ressalvas no seio da esfera pedagógica. Em suma, o empirismo puro e seu princípio subjacente da indução sustentam ambos, a validade da inferência que parte dos exemplos concretos, singulares e/ou particulares e daí tem a pretensão de alcançar a lei geral. Em outras palavras, seria uma crítica a uma concepção do método científico que fosse simplesmente baseado em exemplos particulares concretos como foi, por exemplo, a crítica arrasadora de K. R. Popper ao empirismo puro. No entanto, convenhamos, a passagem do nível epistemológico para o nível pedagógico - tanto do ensino quanto da aprendizagem - não se constitui em algo que possa ser considerado nem mecânico, nem direto e nem tampouco trivial.

Atenhamo-nos, portanto, à recomendação presente, que reputamos como importantíssima, de que a passagem do plano epistemológico para o plano didático-educacional não se constitui em algo que seja minimamente trivial, embora os dois planos tenham também relações íntimas e até mesmo, interseções e indissolubilidades que devem ser exploradas.

E exatamente neste ponto, colocamos os dois seguintes questionamentos.

- Será que a nenhum educador ocorreu a ideia de trabalhar em mão dupla?

- Por que não, além de se percorrer os diversos níveis de abstração partindo do concreto para o abstrato, não se exercita também o caminho inverso de partir do abstrato e geral para o concreto tentando contextualizar situações específicas e particulares? 
Isso talvez seja um indicador, pelo menos parcial, de que não foi o foco na abstração propriamente dita o grande mal e sim a apologia excessiva desta, excluindo-se, por conseguinte, outras formas de pensar igualmente legítimas, necessárias e bem mais concretas.

- No que concerne à segunda revolução não creio que tenha sido o self learning o grande vilão, apesar de achar que ele, por si só, seja claramente insuficiente, pois sem a tradição que nos foi legada ficaremos sujeitos à eterna recorrência da reinvenção da roda, o que nos autoriza a asseverar que a instrução direta de geração para geração é também um elemento imprescindivel. Isso, contudo, não impede a consideração de que a construção idiossincrática do conhecimento, que necessariamente depende de cada indivíduo dotado de potencialidades cognoscitivas amplas, não tenha base na analogia (embora imperfeita) entre a evolução mental das pessoas e a História da Ciência (PIAGET; GARCIA, 1987) e na importância da dimensão de natureza sócio interacionista enquanto um dos elementos provedores do conhecimento, ver (VYGOTSKY, 1991). Deveremos asseverar, além disso, que essa construção individual e idiossincrática, não deve ser deixada apenas sob a responsabilidade do estudante (aprendiz). É necessário aqui enfatizar que o peso do legado da tradição é essencial e se não quisermos reinventar a roda a cada instante do aprendizado, então o professor deve necessariamente intervir para acelerar, ampliar, sistematizar e principalmente melhorar este self learning que, evidentemente, não pode nem deve ser exclusivamente self, pois -repitamos à exaustão- o peso da tradição que nos foi legada, seja para o bem seja para o mal, é imprescindível no processo de aprendizagem e até mesmo, a fim de que no decurso de um processo de aprendizagem em um nível cognitivo alto, o estudante seja dotado de um legado e uma infraestrutura, ambos necessários para a modificação do conhecimento presente. Deste modo, somos muito mais inclinados a crer que não foi propriamente a atitude do self learning que foi a responsável pela desarticulação do ensino sistemático e sim o exagero constituído pelo abandono do imprescindível contraponto do peso da tradição para estimular o estudante $e$ até mesmo para melhorar a sua própria aprendizagem. A exacerbação desse abandono se dá na terceira revolução por razões análogas.

- No que concerne à terceira revolução, a desarticulação se aprofunda e os diversos grupos de estudantes, devido a seus desenvolvimentos idiossincráticos diversos, não mais se entendem e a discussão verbal de conceitos e teorias não mais se dá em detrimento da aprendizagem. Isso mostra que o desenvolvimento da linguagem associado ao conteúdo genuíno é algo de imprescindível importância. Acreditamos que o desenvolvimento da linguagem vá bastante além da habilidade e da capacidade de formular problemas, construir enunciados precisos e rigorosos, separar conceitualmente o fundamental do meramente acessório e exercitar permanentemente a capacidade imprescindível de separar o joio do trigo. 


\section{Uma crítica ao construtivismo baseada nas pesquisas em psicologia cognitiva acerca da memória de trabalho}

A compreensão global de um assunto constitui-se em uma parte da aprendizagem. Claramente, trata-se de uma parte importante, mas necessário se faz enfatizar, que não é a única parte ou aspecto relevante da aprendizagem. A aprendizagem requer também o treino ou o treinamento, que compreendem a automação de alguns procedimentos repetitivos e instrumentais de cálculo entre outras habilidades do gênero. Para consultar pesquisas que vão nessa direção, ver os trabalhos (FESTAS, 2011; DAMIÃO, 2011; CRATO, 2011) bem como as referências neles contidas.

Os teóricos da psicologia cognitiva falam em memória de trabalho, memória de curto prazo e memória de longo prazo. Vejamos alguns exemplos.

Há algumas décadas discutia-se se as crianças deveriam ou não decorar a tabuada. Segundo alguns críticos, a tabuada consistia em um aperreio para a criança e essa não deveria ser submetida a isso, pois se assim o fizéssemos, impediríamos o desenvolvimento livre das potencialidades lúdicas e imaginativas das crianças em atividades que elas poderiam se envolver se sentindo mais felizes e não aperreadas. Não acreditamos, contudo, que decorar a tabuada de maneira instrumental seja um grande sacrifício nem mesmo em algo necessariamente mau. A decoração instrumental deve vir acompanhada de um conceito simples. Não há mal algum em se decorar e, sem pensar, se dizer que 7 vezes 8 redundam 56 se isso vier acompanhado do conceito de que multiplicar 7 com 8 significa somar 7 com 7 oito vezes ou alternativamente, somar 8 com 8 sete vezes. Se tivermos que pensar cada vez que fizermos operações simples, então perderemos tempo precioso. Poder-se-ia inclusive argumentar que em tempos hodiernos isso sequer constitui-se em algo necessário haja vista que qualquer computador portátil de hoje em dia tem tudo isso e muitíssimo mais, e que assim deveríamos poupar as nossas crianças para as atividades mais criativas. Apesar de tudo isso, alguma dose de treinamento e automação de procedimentos é necessária e isso não significa de forma alguma que não persigamos também com afinco o nível da compreensão, que é importantíssimo e imprescindível para uma boa formação intelectual tendo perfeitamente ciência de que este último não pertence ao campo meramente instrumental.

É de bom alvitre argumentar que não seria minimamente razoável que o aprendiz, a cada vez que se depare com cálculos de derivada de uma função $\mathrm{y}=\mathrm{y}(\mathrm{x})$ em relação à variável $\mathrm{x}$, tenha, necessariamente, que aplicar a definição de derivada como o limite da razão incremental quando $\Delta \mathrm{x}$ tende para zero. Tal como na tabuada, ele deve saber de antemão ${ }^{2} \mathrm{o}$ conceito, ou ir amadurecendo o mesmo ao longo do processo de treinamento e, deste modo, deve também já ter aplicado para os casos mais simples a fim de consolidar a sua própria aprendizagem. Mesmo porque, se ele vier a aplicar a definição para qualquer caso em que se confronte, então ele perderá todo o seu tempo calculando derivadas e, por conseguinte, não

\footnotetext{
${ }^{2}$ Senão de antemão, pelo menos o aprendiz deve estar preparado e propenso para saber qual a razão daquele procedimento instrumental.
} 
vai progredir conceitualmente em outras coisas muito importantes. Decerto, atividades mais criativas e que exijam mais iniciativas intelectuais por parte dos aprendizes devem ser incentivadas. Isso, contudo, não significa dizer que certo grau de treinamento repetitivo de um tipo já internalizado como se fosse um piloto automático não tenha também um papel relevante na aprendizagem. Contestar tal opinião ao argumentar que isso os computadores modernos já fazem muito melhor do que qualquer um de nós, embora seja parcialmente pertinente, também não passa de uma meia verdade, pois também nós deveremos estar preparados para enfrentar desafios instrumentais mesmo que sejam sem o recurso dos computadores e/ou outras máquinas. E isso é verdade até se elegermos o fito precípuo de nos tornarmos mais aptos ao exercício de atividades mais criativas. No fundo, é a ideia de não sobrecarregar em demasia a memória de trabalho com uma carga cognitiva excessiva e sim a recomendação de se usar também, procedimentos mais automáticos exercitados por treinamento e repetição, para que tenhamos condições de poder liberar as potencialidades criativas dos aprendizes, estimulando inclusive, segundo algumas correntes hodiernas de psicólogos cognitivos, a liberação importante da memória de longo prazo, seja lá se forem estudantes, seja lá se forem professores.

Deste modo, parece que novamente o caminho do meio é o mais aconselhável. Não podemos nem desconsiderar as atividades lúdicas, imaginativas e todas as faculdades criativas, nem desconsiderar as atividades de treinamento instrumental, mesmo porque não necessariamente essas atividades são tão aborrecidas; ver, por exemplo, os casos de certos jogos.

Em suma, os dois movimentos são necessários e um deles não exclui necessariamente o outro. Aliás, é necessário que tais movimentos não se excluam mutuamente e que, pelo contrário, se potencializem em sinergia. Em outras palavras, concebemos que atividades repetitivas de treino, não são em nenhuma hipótese incompatíveis com atividades criativas e lúdicas que envolvam escolhas diversas. Acreditamos que é nessa complexidade essencial que devemos abordar o complexo e eternamente recorrente processo da aprendizagem. Seguramente, reduzir a atividade de pesquisa ao nível meramente instrumental é algo tão problemático quanto reduzir o aprendizado a apenas atividades lúdicas nas quais estejam ausentes quaisquer atividades de treinamento. Talvez mesmo, por mais estranho que possa parecer, a posição mais radical seja a do caminho do meio ou de algum caminho do meio que persiga sinergias cognitivas.

\section{$X$. A partir do ensino de matemática, o que concluir sobre o ensino de física?}

O congresso internacional de Lisboa sobre o ensino de matemática e sobre a educação matemática em geral, em relação ao qual nos debruçamos com o fito de que venhamos a emitir algumas considerações estimuladas pela leitura e pela reflexão de suas atas, foi dirigido, obviamente, para o encontro de soluções, ainda que parciais, sobre como as crianças, os adolescentes e talvez mesmo alguns adultos possam aprender da melhor maneira possível conteúdos desse campo singularíssimo do conhecimento. De fato, a discussão neste congresso foi muito mais centrada no ensino básico, o que não nos impede de conjecturarmos acerca do 
ensino para outros níveis e para outras faixas etárias. Estamos cientes de que as crianças não são exatamente como os adultos, mas temos a firme convicção, embora não dogmática, de que em qualquer idade que a pessoa esteja, ela pode ser beneficiada com a cognição e que, portanto, somente deixamos de aprender depois de nossas mortes.

Dito isso, cogitemos do problema da passagem do ensino da matemática para o ensino da física, questão essa que apresenta, sem dúvida, pontos de grande interesse para os nossos propósitos.

Coloquemos a seguinte questão:

- Em que sentido, discussões e resultados sobre o ensino de matemática instruem sobre o ensino de física?

Os ensinos de matemática e de física tanto guardam semelhanças evidentes advindas de suas profundas afinidades, bem como também contém diferenças consideráveis. E sobre o caráter singular da matemática, talvez mesmo do caráter singularíssimo dessa, é que radica uma diferença que vale a pena ser explorada brevemente neste artigo.

Para dar um exemplo, diria que muitas pessoas já vieram nos perguntar o porquê de vários mestrados no Brasil adotarem a expressão Mestrado Profissional em Ensino de Ciências e Matemática. As pessoas perguntam:

- Por que ciências por um lado, e matemática por outro?

- A matemática é ou não uma ciência?

Uma resposta mais direta para isso é que a natureza da matemática é diferente da natureza das ciências empíricas como os exemplos das respectivas naturezas da física, da química e da biologia. Nas últimas, o critério de validação de seus resultados seria o diálogo complexo entre teorias e experiências, enquanto no que concerne à matemática o critério, talvez o mais caro aos matemáticos, seja o da consistência lógica, ou no fundo, o da ausência de contradições no seio de suas teorias e esquemas hipotético-dedutivos. Neste sentido estrito, pela sua própria natureza, a matemática não seria uma ciência como as outras, embora, para uma ciência como a física, por exemplo, pelo menos depois da intuição galileana do Grande Livro da Natureza, a conexão da física (antiga filosofia natural) com a matemática passou a assumir um papel de indissolubilidade. Essa seria, grosso modo, uma diferença em nível epistemológico entre a natureza do conhecimento matemático e a natureza do conhecimento de uma ciência de lavra empírica como a física. No entanto, é bom que se diga com a devida ênfase que os próprios matemáticos divergem quando emitem seus pareceres sobre as relações da matemática com a física. De uma maneira panorâmica e generalista, diríamos que para alguns matemáticos o quanto mais abstratamente falarmos dos objetos matemáticos distantes da realidade física, tanto melhor para a matemática, enquanto para outros é a realidade física, entre outras realidades, quem inspira a criação matemática. Esta, todavia, é uma questão complexa e recorrente em cima da qual há muitas divergências e algumas convergências e para a qual remetemos o leitor para o trabalho (BASTOS et al., 2003). 
Além das diferenças epistemológicas entre os dois campos, há outras diferenças de outros teores como, por exemplo, aquelas relacionadas com os procedimentos e atitudes dos pesquisadores das comunidades dedicadas respectivamente ao ensino de física e ao ensino de matemática. Em recente Memorial escrito com o fito de sua Promoção para o nível de Professor Titular da Carreira do Magistério Superior na Universidade Federal do Rio Grande do Norte, o Professor Ciclamio Leite Barreto, ao se referir à mobilização da Associação Brasileira de Pesquisa em Educação em Ciências (Abrapec) em prol da reivindicação para a criação dos Mestrados Profissionais pela Capes, nos primeiros anos do século XXI, relata que essa associação congregou os pesquisadores atuantes nos ensinos de ciências biológicas, de química e de física, mas não no tocante ao ensino de matemática. A este propósito ele escreveu:

A educação matemática não foi contemplada porque já possuía uma entidade para cuidar dos seus interesses, a Sociedade Brasileira de Educação Matemática (SBEM). E também porque a filosofia subjacente e as concepções pedagógicas da educação matemática e da pesquisa sobre ela diferem razoavelmente daquelas das ciências da natureza. Isso torna difícil o diálogo intercomunitário (LEITE BARRETO, p. 57).

No nosso próprio Memorial escrito para a Promoção para o nível de Professor Titular da Carreira do Magistério Superior e apresentado ao Instituto de Física da Universidade Federal de Alagoas (Bastos Filho, 2015) tecemos alguns comentários sobre como fomos sobremaneira beneficiados na nossa formação de estudante de bacharelado em Física pela Universidade Federal da Bahia enquanto frequentávamos em 1967 e 1968, respectivamente aos 18 e 19 anos de idade, as então disciplinas de Física Geral e Experimental I e II, de periodicidades anuais, ocasião em que as nossas turmas cursaram o PSSC (Physical Science Study Committee). Foi um curso conduzido pelo Prof. Felipe Serpa, que décadas após se tornaria reitor da UFBA. Os experimentos realizados aliados às teorias subjacentes e à discussão calorosa sempre incentivada por Felipe Serpa foram de enorme valia para constatar como o diálogo entre teorias e experimentos dão a tônica de como os físicos de fato trabalham, e não a ideia ingênua de 'olhar para a natureza para ver como ela funciona', como se pudéssemos concluir qualquer coisa que seja sem que tivéssemos de antemão algum conhecimento prévio, ou seja, nada concluiríamos sem que de antemão assumíssemos alguns a priori sobre a realidade a ser estudada. Depois aprendemos que mesmo com esses a priori que ao serem adotados nos permitiam constatar algumas leis, mesmo com esses, ainda assim estaríamos sujeitos a novas revisões e a radicais mudanças. E é assim que o conhecimento da realidade física se processa. $\mathrm{Na}$ época, colegas questionavam sobre problemas políticos e pedagógicos relativos à aplicação do PSSC, entre eles o da conexão com a matemática que, segundo eles, era no nível elementar para um curso universitário. Felipe argumentava que com o PSSC estaríamos mais aptos a enxergar as conexões com o cálculo infinitesimal que concomitantemente aprendíamos, do que se estivéssemos estudando pelo livro do Resnick e Halliday. Tempos depois concordamos com o argumento de Felipe Serpa de que subjacentemente havia matemática 
sofisticada já presente no PSSC e que a exploração dessas conexões também nos fez melhorar a nossa compreensão do cálculo diferencial e integral inclusive. Para detalhes relacionados direta e indiretamente ao argumento ver (BASTOS FILHO, 2011; 2014; 2015).

Vejamos agora que há críticas ao construtivismo também de teores diversos daqueles que aqui estamos até então discutindo.

\section{Uma crítica ao construtivismo em um viés predominantemente político}

Desnecessário afirmar que a educação, qualquer que seja ela, não é neutra. A educação trata de conhecimentos, valores, atitudes e procedimentos e, como tal, está indissoluvelmente ligada a poderes, a conflitos, à luta entre grupos de pessoas, entre classes sociais e entre grandes concepções acerca do mundo. A educação, portanto, não poderá estar alheia à dimensão multicultural e nem à dimensão pluricultural. Por essa razão é sempre uma batalha a ideia de educação inclusiva. Para incluir quem? Para excluir quem? A verdadeira luta democrática radica na batalha para incluir cada vez mais pessoas e isso também não é isento de conflitos, pois a inclusão social pela educação - que é muito mais importante do que a inclusão apenas pelo consumo e pelo mercado - pode irritar setores privilegiados.

Não desconhecemos isso e nos balizamos também por isso. No entanto, se elevarmos o tom ideológico além daquilo que seria razoável, então poderemos dar com os burros na água.

O Prof. Newton Duarte da UNESP exibiu uma série de vídeos educativos criticando o lema Aprender a aprender de lavra claramente construtivista, se por construtivismo viermos a conceber a ideia guarda-chuva contida na ênfase emprestada ao conhecimento prévio do aprendiz, enquanto sujeito do conhecimento, e à necessidade de que o aprendiz construa o seu próprio conhecimento e, que, portanto, a partir daí seja um protagonista da construção de seu próprio saber.

Duarte concebe que esse lema contém quatro princípios valorativos subjacentes que ele considera negativos. $\mathrm{O}$ primeiro de tais posicionamentos valorativos subjacentes ao lema Aprender a aprender que ele constata que está presente tanto nos educadores Escolanovistas como também no próprio Piaget é o da desvalorização do ato de ensinar. Segundo Duarte, o lema Aprender a aprender contem subjacentemente a ideia de que é melhor aprender sozinho do que com os outros. Deste modo, podemos interpretar, que, nesse lema, nem o aspecto social do aprendizado nem sequer o próprio ato de ensinar assumiriam quaisquer primazias.

Duarte vê um segundo posicionamento valorativo negativo no lema Aprender a aprender também no que diz respeito ao aspecto da primazia conferida ao processo em detrimento do conhecimento legado pela enorme tradição cultural da humanidade. Em outras palavras, o processo seria mais importante do que o próprio conhecimento do qual já dispomos e que nos foi legado pelas gerações que nos precederam. Em ainda outras palavras, subjaz ao lema Aprender a aprender o posicionamento valorativo segundo o qual, o método (o método científico, talvez) seja mais importante do que os resultados já obtidos. 
Há, conforme Duarte, um terceiro posicionamento valorativo carregado pelo lema Aprender a aprender que consiste em subjacentemente insinuar a tese de uma espécie de contínua obsolescência. Argumenta ele que a lógica subjacente a esse lema é a seguinte: já que o conhecimento atual entra bem rápido em obsolescência, então deveríamos dar maior primazia à nossa capacidade de sempre buscar novos conhecimentos do que simplesmente os adquirirmos. O preparar-se para vencer a luta contra a contínua obsolescência do conhecimento passa, segundo ele, a adquirir um objetivo da educação que se reduz a mero utilitarismo e a mero instrumentalismo. E esse objetivo impede que a escola e os próprios educadores tenham seus próprios objetivos precípuos do que seja educar.

Há ainda, conforme o que pensa Duarte, um quarto posicionamento valorativo carregado neste lema Aprender a aprender, pois devemos sempre estar capacitados a atender às exigências da sociedade na qual vivemos. Isso implica em termos de adquirir, forçosamente, uma grande capacidade adaptativa. Capacidade adaptativa para atender a quais demandas? As demandas do mercado?

Duarte conclui então que uma educação balizada pelo Aprender a aprender seja apenas restrita a uma educação burguesa, neoliberal, que privilegia os interesses de mercado e, por conseguinte, uma educação baseada em tais diretrizes não poderá, por inerente incapacidade, vir a ser uma educação crítica nem tampouco transformar-se em uma educação que seja genuinamente libertadora.

Não obstante concordar que o raciocínio pode ser considerado como bem construído e, sem dúvida, pertinente, questionemos aqui acerca da possibilidade, também pertinente, se viermos a pensar de outro modo. Creio que ganharemos se transformarmos este ponto em um feliz ensejo de uma controvérsia fértil.

\section{O outro lado da moeda}

O lema Aprender a aprender pode ser, sem dúvida, um estratagema de uma educação burguesa de lavra neoliberal, por exemplo, a fim de que sejam preparados contingentes e mais contingentes de pessoas que não precisam se apegar a legados culturais mais sólidos e, sim que sejam pessoas que se adaptem às exigências do mercado e aos novos tempos. Deste modo, uma educação que reduz os indivíduos a peças de um sistema que serve a interesses empresariais e de mercado, não poderá se constituir em uma educação libertadora das faculdades espirituais mais altas dos educandos.

Todavia, vamos agora pensar de outra maneira e tecer considerações de outra lavra.

Perguntemos:

- Ora, o Aprender a aprender também não poderá - contrariamente ao que se disse anteriormente - se constituir em um encorajamento para que os educandos alcancem as suas autonomias enquanto seres pensantes?

E de antemão diremos que classificar os esforços de alcançar a autonomia como desideratos burgueses e neoliberais constitui-se em algo que não se sustenta de forma alguma. 
Rigorosamente, todos nós somos sujeitos da educação e jamais deixaremos de sê-lo. Perguntemos então,

- Se nós estivermos continuamente preparados para Aprender a aprender, não para desprezar a boa tradição da qual somos tributários, nem para vencer desafios de mercado, e sim para nos tornarmos aptos a desafios de outras ordens como deixar o melhor possível de nós próprios para as gerações vindouras, então isso não deveria se constituir numa educação verdadeiramente libertadora e emancipadora?

Para haver educação realmente genuína, faz-se necessário encorajar o protagonismo de homens e mulheres de grandeza que pensem na elevação do espírito humano como possibilidades, inclusive ainda enquanto possibilidade meramente utópica, e não em exigências de mercado, meras utilidades e quaisquer outras situações que não favoreçam plenamente o exercício das mais altas faculdades morais, éticas e cognitivas dos seres humanos. Lembremos que as utopias não perdem o seu valor pelo simples fato de não serem realizáveis. Basta que elas apenas sejam muito parcialmente realizáveis e ainda que elas não sejam nem minimamente realizáveis, ainda assim manteriam a sua mais alta dignidade. Nesta altura, vamos nos valer do poeta ao dizermos que se as estrelas são inalcançáveis, mesmo assim elas serão infinitamente benéficas, pois de outra qualquer maneira quão tristes seriam as caminhadas noturnas dos viajantes!

\section{A Paideia grega como referência}

Werner Jaeger escreveu um famoso ensaio no qual apresentou uma extraordinária singularidade grega: a Paideia. Asseverou Jaeger já na Introdução de seu seminal livro que conceitos por demais amplos tais como filosofia e cultura são difíceis de ser formulados adequadamente em enunciados simples. O mesmo se dá com a Paideia. Neste sentido, insiste Jaeger, que nenhuma das expressões modernas como civilização, cultura, tradição, literatura ou educação exatamente coincidem com o sentido original grego da Paideia e, por isso, como cada uma dessas expressões ressaltaria tão somente um dos aspectos do conceito amplo de Paideia, então, para abordá-la adequadamente teríamos que lançar mão de todos esses conceitos a uma só vez.

É possível e até mesmo bastante provável que quando hoje dizemos que o objetivo de uma educação que seja libertadora não se reduz à dimensão cognitiva do ato de educar e que são também imprescindíveis incluir as dimensões éticas e políticas encerradas na necessidade do exercício da cidadania e da exibição de valores altos, atitudes proativas e procedimentos que revelam grandeza de espírito, então estamos falando, de alguma maneira, de um dos ecos da Paideia grega. Mas muito cuidado! Aqui, usamos expressões modernas como, por

\footnotetext{
3 "Se as coisas são inatingíveis... ora! Não é motivo para não querê-las... Que tristes os caminhos, se não fora a presença distante das estrelas!", Das Utopias (MARIO QUINTANA). Ver <http://kdfrases.com/autor/marioquintana/3>.
} 
exemplo, o termo 'proativo' que não sabemos o significado correspondente grego e nem sequer se há ou não uma correspondência precisa e não ambígua. Trata-se do problema do anacronismo tão enfatizado pelos historiadores, problema esse que consiste, grosso modo, em analisar o passado conforme nossos olhos do presente. Fica, portanto, a provocação.

\section{Nem tanto o mar nem tanto a terra}

Sem dúvida, temos necessidade de construir conhecimento, pois do contrário, não poderíamos alcançá-lo sem que de antemão não lançássemos mão de alguns a priori sobre o mundo a fim de contorná-lo. Se adotarmos este significado de construtivismo para a revolução copernicana à la Kant, então o construtivismo no plano epistemológico é inevitável. Mas isso não significa nem que somente aprendemos sozinhos, nem que somente aprendemos com o legado com o qual fomos contemplados. Aprendemos de fato nas duas vias e muito mais. Há, portanto, imperiosa necessidade de ponderar os múltiplos aspectos envolvidos no complexo fenômeno da aprendizagem para que venhamos a ter uma visão mais abrangente e relativamente confiável, embora nada disso seja empreendimento simples. É no fundo aquela história de radicalizar sem ser extremista, ou seja, assumir a necessária postura socrática de modéstia e, consequentemente, de superação daquela agrestia, essa sim extremista e fundamentalista, de não respeitar a divergência, pois qualquer um de nós, sem exceção, somente poderá ter uma razão ligeiramente parcial, em tudo o que a gente diz e pensa. As controvérsias são, portanto, necessárias para formamos juízos e concepções de mundo.

\section{O debate precisa ir além do confronto em torno da cognição}

Se tomarmos lemas construtivistas como Aprender a aprender, aprender por si próprio, o estudante deve estar no centro, aprender por descoberta, ser protagonista de sua própria aprendizagem, o professor é mero facilitador entre vários outros lemas de lavras construtivistas do gênero, e deixarmos o leitor interpretar por si próprio o que, no seu parecer, significam tais lemas, então tudo isso pode ser entendido de muitas e diversificadas maneiras.

Pode aparecer um crítico, como Newton Duarte, que enxergará nisso uma apologia ao utilitarismo, ao pragmatismo e ao individualismo o mais ensimesmado possível, e por isso devemos advertir as pessoas para o perigo de que os sujeitos da educação venham a eleger como primazia os processos e não os resultados, mediante o argumento, segundo ele nefasto, de que a obsolescência contínua no mundo moderno são desafios para os mais competitivos, pois assim esses estariam mais adaptados às exigências do mercado. Conclui Duarte que uma educação do gênero não pode ser nem revolucionária nem libertadora.

Pode aparecer, por outro lado, alguém que considere este desafio, não propriamente como prover a habilidade de se tornar competitivo para o atendimento das exigências do mercado e sim para que alcancem autonomia no sentido lato do poder de julgar por si próprios, e em sinergia com os demais, o que de relevante for para ser dirimido e decidido. Inclusive para 
se tornar hábil para confrontar as exigências escravizadoras dos mercados. Aqui não se trata de adaptação nenhuma a mercados de trabalho ou a algo do gênero e sim de capacitação de autonomia intelectual, e por extensão, de autonomia política para tomar decisões, inclusive decisões políticas contrárias ao status quo. Sendo assim, não há porque uma educação que persiga tão nobres fins não tenha condições de ser libertadora, se acreditarmos que a educação, em algum dos muitos significados da Paideia grega, tenha possibilidade de se tornar libertadora em algum grau.

\section{O que podemos concluir}

Chegamos ao estágio de nossa reflexão em que temos que ir fechando algumas conclusões a respeito daquela concepção chamada de construtivismo em relação à qual os seus críticos severos, ao reconhecerem que se trata de uma concepção dominante no contexto da educação, não deixam de lamentar essa hegemonia ao tempo em que veementemente alertam para os perigos que, segundo os seus respetivos pareceres, representariam as enormes distorções e consequências e tudo isso em detrimento daquilo que seria um ensino genuinamente articulado e de qualidade.

Pelo que conhecemos e pela nossa própria experiência sustentamos que não há razão alguma para que adotemos posições ideológicas nem que deixemos de olhar para os argumentos de todos os intervenientes no debate. Trata-se de um debate eternamente recorrente, em cima de um tema difícil, realmente muito difícil e recorrente.

Por mais sofisticado que seja o debate centrado no aspecto cognitivo, ele é ainda muito parcial, na medida em que a educação para a cidadania transcende, embora não prescinda dos conteúdos estritamente científicos com os quais trabalha. Questões importantes como a autonomia dos sujeitos, a autonomia das escolas e das universidades, as decisões sobre os organismos transgênicos, sobre a saúde pública, sobre a carreira docente, sobre os sistemas de avaliação, sobre a crise da democracia representativa, sobre a matriz energética, sobre o meio ambiente, entre vários outros, são temas que não são neutros de forma alguma e que por suas inerentes complexidades precisam ir além, e de fato ir muito além da mera cognição por mais imprescindível que esta seja - pois valores, atitudes e procedimentos éticos são, pelo menos, igualmente necessários. Além disso, por serem inerentemente políticos, pertencem ao que chamamos de educação científica no sentido lato do termo.

\section{Conclusões}

São as doenças infantis e perigosíssimas do fundamentalismo e do extremismo que impedem uma pessoa de ser radical no bom sentido do radicalismo. O radical, contrariamente àquilo que habitualmente se concebe, exatamente pelo fato de ir à raiz dos problemas, passa então a constatar a inerente complexidade dos mesmos e, precisamente por isso, adota a postura socrática da imprescindível modéstia, além da recomendável cautela intelectual. Deste 
modo, passa a ser prudentemente ponderado, e tal como o próprio significado do termo ponderação encerra, procura atribuir pesos às categorias intervenientes. Como não há soluções que sejam panaceias para a educação científica, o radical, neste estrito sentido e não no habitual sentido do radicalismo, procurará diuturnamente eleger quais são, a seu ver, os critérios que lhes pareçam os mais justos e razoáveis. Exatamente por seu sincero compromisso a um só tempo, ético e cognitivo, estará o radical sempre disposto a rever os seus argumentos e melhorá-los. O interesse do radical - diferentemente do interesse do extremista e do fundamentalista - é o de acercar-se tanto quanto possível de uma solução razoável. No fundo, no fundo trata-se da recomendação aristotélica de que a virtude esteja no meio. Isso, somente parecerá 'estar em cima do muro' apenas para os espíritos toscos e talvez mesmo esta seja a solução mais radical na conotação que queremos emprestar ao radicalismo.

Desta reflexão, concluímos que as adoções para o ensino de ciências que adotam a necessidade do conhecimento prévio e do protagonismo do sujeito que aprende e constrói o seu próprio conhecimento as quais, grosso modo são rubricadas como construtivistas, não são incompatíveis com adoções que também emprestem centralidade ao protagonismo do professor e, mais geralmente, que emprestem imprescindível papel desempenhado pelo legado cultural que o sujeito que aprende recebe, modifica e transforma pela sua atuação no mundo. Uma elipse, por exemplo, tem dois focos e, portanto dois centros, e se esta puder representar uma imperfeitíssima metáfora do processo complexo da aprendizagem, então não poderemos deixar de considerar que neste complexo processo vige uma pluralidade de centralidades ativas e não apenas uma. Ademais, é possível contemplar, baseado nos conceitos de memória de trabalho tão insistentemente trazidos à baila pelos psicólogos cognitivos, que não é de forma alguma incompatível com as concepções construtivistas de protagonismo do sujeito que aprende construindo o seu próprio conhecimento, que procedimentos de rotina, automáticos de treinamento sejam internalizados a fim de liberar espaço para habilidades, competências e funções nobres do processo de criação. E assim concluímos a nossa reflexão.

\section{Referências}

AHARONI, R. Three Principles in the Teaching of Mathematics and what happens when they are circumvented. In: CONFERÊNCIA INTERNACIONAL MATEMÁTICA ENSINO: Questões e Soluções, 2008, Lisboa, Fundação Calouste Gulbenkian. Anais publicados em Lisboa, julho de 2011. p. 41-51.

ARAÚJO, L. O problema do ensino em contexto é que pode ser muito limitativo. In: CONFERÊNCIA INTERNACIONAL MATEMÁTICA ENSINO: Questões e Soluções, 2008, Lisboa, Fundação Calouste Gulbenkian. Anais publicados em Lisboa, julho de 2011. p. 63-68

BASTOS, B. L. G. B.; BASTOS FILHO, J. B. Conflitos entre Escolas de Pensamento da Matemática: exploração de potencialidades para melhoria dos ensinos da Matemática e da Física. 
Investigações em Ensino de Ciências, v. 8, n. 1, p. 53-90, 2003. Disponível em: $<$ http://www.if.ufrgs.br/ienci/artigos/Artigo_ID97/v8_n1_a2003.pdf>.

BASTOS FILHO, J. B. A História da Ciência e a Filosofia da Ciência ajudam, atrapalham ou são irrelevantes para o Ensino de Física? Norte Ciência, v. 2, n. 2, p. 111-125, 2011. Disponível em: <http://aparaciencias.org/vol-2.2/15_Jenner_p.111-125.pdf >.

BASTOS FILHO. J. B. Diálogos entre a pesquisa em educação, a pesquisa em física e a pesquisa em ensino de física: pontos de aproximação e de afastamento. In: CAMARGO, S.; GENOVESE, L. G. R.; DRUMMOND, J. M. H. F.; QUEIROZ, G. R. P. C.; NICOL, Y. E.; NASCIMENTO, S. S. (Orgs.). Controvérsias na Pesquisa em Ensino de Física. São Paulo: Livraria da Física, 2014. p. 245.

BASTOS FILHO, J. B. Memorial Acadêmico apresentado ao Instituto de Física da Universidade Federal de Alagoas em vista de Promoção para o nível de Professor Titular da Carreira do Magistério Superior, Maceió, Alagoas, 2015.

BRAGA GARCIA, T. M. F. As dimensões da experiência escolar e o ensino: contribuições para um diálogo sobre pesquisa. In: CAMARGO, S.; GENOVESE, L. G. R.; DRUMMOND, J. M. H. F.; QUEIROZ, G. R. P. C.; NICOL, Y. E.; NASCIMENTO, S. S. (Orgs.). Controvérsias na Pesquisa em Ensino de Física. São Paulo: Livraria da Física, 2014. p. 265

CRATO, N. (Org.) Matemática Ensino: Questões e Soluções. In: CONFERÊNCIA INTERNACIONAL MATEMÁTICA ENSINO: Questões e Soluções, 2008, Lisboa, Fundação Calouste Gulbenkian. Anais publicados em Lisboa, julho de 2011.

CRATO, N. Ensinar matemática temperando a experiência com as recomendações da Ciência Moderna. In: CONFERÊNCIA INTERNACIONAL MATEMÁTICA ENSINO: Questões e Soluções, conferência realizada em novembro de 2008, CRATO, N. (Org.), Lisboa, Fundação Calouste Gulbenkian, Anais publicados em julho de 2011, p. 241-267

DAMIÃO, M. H. Orientações curriculares para a matemática no ensino básico: fundamentação pedagógica cognitivista ou construtivista? In: CONFERÊNCIA INTERNACIONAL MATEMÁTICA ENSINO: Questões e Soluções, 2008, Lisboa, Fundação Calouste Gulbenkian. Anais publicados em Lisboa, julho de 2011. p. 161-168

DUARTE, N. Teorias Pedagógicas (Crítica ao Aprender a Aprender). Disponível em: $<$ https://www.youtube.com/watch?v=Am_-6pZIyVw>.

DUARTE, N. Teorias Pedagógicas (O Construtivismo, parte 1) Disponível em: $<$ https://www.youtube.com/watch?v=ySANEiR4t6A >.

DUARTE, N. Teorias Pedagógicas (O Construtivismo, parte 2) Disponível em: $<\mathrm{https}$ //www.youtube.com/watch?v=tJk_Bm6Vsn0>. 
FESTAS, M. I. F. Contrariamente a certas teses construtivistas, a aprendizagem depende em grande parte da aquisição de fatos e procedimentos. In: CONFERÊNCIA INTERNACIONAL MATEMÁTICA ENSINO: Questões e Soluções, 2008, Lisboa, Fundação Calouste Gulbenkian. Anais publicados em Lisboa, julho de 2011. p. 153-160

JAEGER, W. Paideia: los ideales de la cultura griega. México: Fondo de Cultura Económica 1957.

LEITE BARRETO, C. Memorial Acadêmico apresentado ao Instituto de Física da Universidade Federal do Rio Grande do Norte em vista de Promoção para o nível de Professor Titular da Carreira do Magistério Superior, Natal, Rio Grande do Norte, Brasil, 2015.

MATTHEWS, M. Construtivismo e o ensino de ciências: uma avaliação. Caderno Catarinense de Ensino de Física, v. 17, n. 3, p. 270-294, dez. 2000.

PIAGET, J. A psicogênese dos conhecimentos e a sua significação epistemológica. In: PIATELli-PALMARINI (Org.). Jean Piaget \& Noan Chomsky debatem Teorias da Linguagem e Teorias da Aprendizagem. Lisboa: Edições 70, 1987. p. 51-62,

PIAGET, J.; GARCIA, R. Psicogênese e História da Ciência. Tradução: Maria F. M. R. Jesuíno. Lisboa: D. Quixote (originalmente publicado em 1983), 1987.

TEIXEIRA, A. A Universidade de Ontem e de Hoje. In: NUNES, C. (Org. e Introdução). Rio de Janeiro: Editora da Universidade do Estado do Rio de Janeiro (EdUERJ), 1998.

VYGOTSKY, L. S. A Formação Social da Mente. In: COLE. M.; JOHN-STEINER, V.; SCREIBNER, S.; SOUBERMAN, E (Orgs.). Tradução: José Cipolla Neto, Luis Silveira Mena Barreto, Solange Castro Afeche. São Paulo: Livraria Martins Fontes Editora Ltda, 1991.

Ver página eletrônica: <http://www.egov.ufsc.br/portal/sites/default/files/vygotsky-aformac3a7c3a3o-social-da-mente.pdf $>$.

ZYLBERSZTJN, A. Contribuição para a mesa redonda "Diálogos entre a pesquisa em educação, a pesquisa em física e a pesquisa em ensino de física: pontos de aproximação e de afastamento". In: CAMARGO, S.; GENOVESE, L. G. R.; DRUMMOND, J. M. H. F.; QUEIROZ, G. R. P. C.; NICOL, Y. E.; NASCIMENTO, S. S. (Orgs.). Controvérsias na Pesquisa em Ensino de Física. São Paulo: Livraria da Física, 2014. p. 237. 